the number of such posts and the part they play in career progression." The factors determining competition for consultant posts are the number of people who at any one time occupy posts with training recognition, and the minimum period required in such posts. Without control over the first of these and clear understanding of the second the system is unmanageable.

The third of JPAC's tasks concerned quotas of posts for regions. For this the committee devised an allocation formula giving a weighting of $30 \%$ to the number of medical and dental students in the region, $50 \%$ to the regional population adjusted according to the formula of the Resource Allocation Working Party, and only $20 \%$ to the expected number of consultant vacancies in the region. This formula, intended to offer rough justice, weights student numbers more than was originally proposed. Though there may be a discernible link between numbers of undergraduates and numbers of senior registrars (and perhaps in some places senior registrars are relied on more than they should be to teach students), the relation seems too tenuous to justify a substantially increased weighting. Again the JPAC report, commenting on the high concentration of senior registrar posts in London, refers to the raison d'être of the London postgraduate teaching hospital special health authorities as being "precisely to provide a national training resource." Historical reasons of this kind are not a sound basis for future policies. Good training centres, research facilities, and career opportunities are far more evenly spread throughout the regions than are senior registrars. If there is not a self evident and acknowledged need for change in this state of affairs JPAC has little purpose. The formula requires no region to lose more than one senior registrar a year in a specialty and provides for posts funded by the MRC and similar bodies to be excluded from the regional quota allocations. On this basis the rate of change must be disappointingly slow for many regions, and the first year's allocations show little change except in specialties in which the total number of senior registrars across the country has increased. In any case the committee's concentration on senior registrars is relatively unimportant in the wider context of the profession's problems with its career structure.

All that said, JPAC has made a useful start in analysing the problems and assembling necessary data at a time when the DHSS, the universities, the research establishment, and the profession are all under pressure. Unfortunately, previous failures to act decisively on manpower because of misunderstanding, intransigence, vested interests, or sheer inability to manage the system give scant cause for optimism. The outcome for JPAC's work may well be a test of whether medical manpower planning is to be treated seriously in the NHS.

J PARKHOUSE

Director

Medical Careers Research Group,

Churchill Hospital,

Oxford OX3 7LJ
If correctly managed a young woman with a malignant ovarian germ cell tumour has a better than $85 \%$ chance of being cured and a good chance of remaining fertile. These malignant tumours account for about $3 \%$ of all ovarian neoplasms, and half are dysgerminomas. Doctors need to revise their belief that some histological types have a hopeless prognosis. In fact a treatment can be selected to preserve fertility as well as life.

Gynaecologists should consider that an ovarian mass may be a germ cell tumour when the patient is under 30 , when the mass has solid areas on ultrasound examination, and when certain tumour markers are produced. Serum assays detect raised activity of placental alkaline phosphatase in many patients with dysgerminomas and raised concentrations of $\alpha$ fetoprotein or human chorionic gonadotrophin, or both, in most patients with malignant non-dysgerminomatous germ cell tumours.

For patients with ovarian germ cell tumours a unilateral salpingo-oophorectomy is preferable to a more radical operation. The entire peritoneal contents, however, require inspection through a midline incision, washings are needed for cytological examination, and if it looks suspicious the contralateral ovary requires biopsy. If a pure dysgerminoma is found and there is no clinical evidence of spread, a normal computed tomogram, and normal concentrations of tumour markers then the patient may simply be closely followed up rather than actively treated..$^{23}$ Patients without metastases will avoid toxic treatment, and relapse can be successfully treated.
Many patients with non-dysgerminomatous tumours that have not metastasised have hitherto been treated with vincristine, actinomycin $\mathrm{D}$, and cyclophosphamide, and about $80 \%$ have survived long term. ${ }^{4}$ More toxic treatment with cisplatin, vinblastine, and bleomycin leads to almost $100 \%$ survival. ${ }^{5}$ Because many would probably have survived without chemotherapy and relapses can now be treated, close surveillance is being studied as a treatment option. ${ }^{6}$

When a dysgerminoma has metastasised only to the pelvic area radiotherapy will free about $90 \%$ of patients from disease, but it is less effective against more advanced disease..$^{23} \mathrm{~A}$ similar result can be obtained in patients with advanced dysgerminomas given combination chemotherapy including cisplatin and etoposide, ${ }^{6-8}$ and-in contrast to those receiving radiotherapy-most remain fertile. ${ }^{9}$

The results are as good in patients with advanced nondysgerminomatous tumours provided the patients have not already received radiotherapy or chemotherapy..$^{5-7}$ Cisplatin, vinblastine, and bleomycin are more effective than vincristine, actinomycin D, and cyclophosphamide, and replacing vinblastine by etoposide reduces the toxicity..$^{410}$ It is not clear whether these regimens are as effective as cisplatin, vincristine, methotrexate, and bleomycin alternating with actinomycin D, cyclophosphamide, and etoposide especially in patients with widespread metastases or high concentrations of tumour markers, or both. ${ }^{6}$. Residual masses must be resected and examined to confirm that they do not contain active tumour or differentiated teratoma.

Because of the rarity and curability of malignant ovarian 
germ cell tumours patients who have them should be managed in specialist centres so they receive optimal surveillance or treatment.

Senior Lecturer in Medical Oncology,

Cancer Research Campaign Laboratories,

Charing Cross Hospital,

London W6 8RF, and

Honorary Consultant Physician,

Mount Vernon Hospital,

Northwood, Middlesex

1 Rustin GJS. Tumour markers in germ cell tumours. Br Med $\mathcal{F}$ 1986;292:713-4.

2 Lucraft HH. A review of thirty-three cases of ovarian dysgerminoma emphasising the role of radiotherapy. Clin Radiol 1979;30:585-9.

3 Gordon A, Lipton D, Woodruff JD. Dysgerminoma: a review of 158 cases from the Emil Novak Ovarian Tumor Registry. Obstet Gynecol 1981;58:497-504.

4 Slayton RE, Park RC, Silverberg SG, Shingleton H, Creasman WT, Blessing JA. Vincristine, dactinomycin, and cyclophosphamide in the treatment of malignant germ cell tumours of the ovary. Cancer 1985;56:243-8.

5 Taylor MG, Deptrillo AD, Turner AR. Vinblastine, bleomycin, and cisplatin in malignant germ cell tumours of the ovary. Cancer 1985;56:1341-9.

6 Newlands ES, Bagshawe KD. Advances in the treatment of germ cell tumours of the ovary. In: Bonnar J, ed. Recent advances in obstetrics and gynaecology. Edinburgh: Churchill Livingstone,
1987:143-56.

7 Smales E, Peckham MJ. Chemotherapy of germ-cell ovarian tumours: first line treatment with etoposide, bleomycin and cisplatin or carboplatin. Eur f Cancer Clin Ocol 1987;23:469-74.

8 Gershenson DM, Wharton T, Kline RC, Larson DM, Kavanagh JJ, Rutledge FN. Chemotherapeutic complete remission in patients with metastatic ovarian dysgerminoma. Cancer 1987;58:2594-9.

9 Pektasides D, Rustin GJS, Newlands ES, Begent RHJ, Bagshawe KD. Fertility after chemotherapy for ovarian germ cell tumours. Br f Obstet Gynaecol 1987;94:477-9.

10 Williams SD, Birch R, Einhorn LH, Irwin L, Grego FA, Loehrer PJ. Treatment of disseminated germ-cell tumours with cisplatin, bleomycin, and either vinblastine or etoposide. $N$ Engl f Med 1987;316:1435-40.

\section{Growing up with chronic renal failure}

Advances in managing end stage renal failure in children have improved both the three year survival-from $80 \%$ of those starting in 1976 to $87 \%$ of those starting in 1982 (European Dialysis and Transplant Association Registry, 1987 unpublished observations)-and the physical well being of the survivors. Nevertheless, many uraemic children grow poorly and enter puberty late, and all of those who reach end stage renal failure will need medical supervision for the rest of their lives. The quality of their lives may thus be profoundly affected by their psychosocial adjustment, and helping with this presents a continuing challenge to those who care for them. What satisfaction is there in preserving the life of a child if the treatment leaves him an emotionally handicapped adult? Much remains to be learnt about how to help the children who do not adapt well.

In a study of 38 uraemic children, half of them undergoing dialysis, Reynolds and others reported that threats to psychosocial adaptation identified in the early 1970s are still as important and as difficult to treat. ${ }^{1-3}$ Stress and anxiety in the patients and families may arise from four main sources: adjustment to the uraemic state; problems of growth and unrealistic expectations of the future; practical problems such as enuresis, frequent visits or admissions to hospital, and dialysis itself; and the need for both financial and psychological support for the family.

Difficulties in adjusting to uraemia are particularly great for adolescents and for families with pre-existing marital stress. Families are often ignorant of the available community services, and some suffer from conflicting advice because of poor communication between the hospital services and general practitioners or community agencies. Some parents can, however, turn the stresses into a source of strength for their marriage ${ }^{4}$ and we have found that most children undergoing dialysis have indices of self image within the normal range (Winkley and Winterborn, unpublished observations).

The chief requirement for successful psychosocial adjust- $\overline{\bar{J}}$ ment seems to be a realistic acceptance by the whole family of 7 the limitations imposed by end stage renal failure. The $\$$ adjustment will be easier given consistent expert advice, 肾 practical and financial help, and, above all, time for giving and assimilating information so that it can be used to change the family's pattern of life. These needs have long been $\bar{C}$ recognised by the medical and nursing staff of paediatric $\frac{\bar{F}}{\bar{T}}$ dialysis units, which have enlisted the help of the child $\frac{\text { क }}{\sigma}$ psychiatrist, psychologist, social worker, dietitian, and $\stackrel{\mathbb{Q}}{\varrho}$ school teacher. The family practitioner has an important job is to support the family as well as the patient and to interpret $\overrightarrow{0}$ the messages from the dialysis unit. He must be kept well informed. The social worker and family practitioner between $\stackrel{\omega}{\omega}$ them will usually have the most complete knowledge of local community services. Insufficient recognition is given to the telephone network, fostered by parents' meetings, whereby experienced families help newcomers and those whose children have not yet started dialysis.

In helping children and their families come to terms with end stage renal failure everyone must give the same message 8 about the child's capabilities and prognosis; conflicts are $\frac{}{3}$ common and are likely to hinder adaptation. ${ }^{1}$ The most $\vec{\circ}$ important ingredient of successful adaptation to end stage $O$ renal failure is probably time to talk and listen.

\section{H WINTERBORN}

Consultant and Paediatric Nephrologist,

Regional Paediatric Dialysis Unit,

East Birmingham Hospital,

Birmingham B9 5ST

1 Reynolds JM, Garralda ME, Jameson RA, Postlethwaite RJ. Living with chronic renal failure. Child Care Health Dev 1986;12:401-7.

2 Korsch BM, Fine RN, Grushkin CM, Negrete VF. Experience with children and their families during extended haemodialysis and kidney transplantation. Pediatr Clin North Am 1971;18: 625-37.

3 Raimbault G. Psychosocial aspects of chronic renal failure and haemodialysis. Nephron 1973;11: $252-60$.

4 Matthews DE, Van Leeuwen JJ, Christensen L. Psychosocial problems of young children and their families in a dialysis transplant program. Dialysis and Transplantation 1981;10:73-80.

\section{Chemotherapy for stomach}

\section{cancer}

In Britain stomach cancer is still the third commonest cause of death from cancer in men and the fourth commonest in women. 'An operation is the only cure, and less than $10 \%$ of patients survive long term. ${ }^{2}$ Despite distant metastasis being rare at presentation or relapse in most patients, radiotherapy $\bar{\Phi}$ has been considered to have limited value because of the $\stackrel{?}{?}$ tumour's lack of radiosensitivity. Chemotherapy has therefore been explored as treatment for advanced stomach cancer and as an adjuvant to an operation.

Caution is necessary in interpreting the results of trials of $\stackrel{\mathbb{D}}{\stackrel{2}{\circ}}$ chemotherapy in gastric cancer. Disease response is difficult ${ }^{2}$ to measure, ${ }^{3.5}$ yet in many studies response rates rather than 8 survival have been used to determine the efficacy of treatment. Comparing trials is not easy because of diverse entry 